\section{JMR Rapid Publication Communications}

Since its inception, the Journal of Materials Research has encouraged short, particularly topical, contributions designated as Communications. Such contributions are presently limited to four published pages. Commencing with this announcement, we will institute new procedures designed to assure more rapid publication of $J M R$ Communications. Following are the revised procedures and guidelines:

- The Communications editor will be Patrick K. Gallagher.

- New, particularly topical results may be designated Communications provided their total length is four or less published pages. (A typed double-spaced $81 / 2^{\prime \prime} \times 11^{\prime \prime}$ equivalent is approximately 10 pages.)

- Manuscripts should be mailed to the $J M R$ Editorial Office, Materials Research Society, 9800 McKnight Road, Pittsburgh, PA 15237, and clearly designated Communications. Authors must include a cover letter which includes mailing address, phone and fax numbers (and e-mail address if available). Also, a copyright and index form should be included. A copy of these can be obtained from the back of $J M R$.

- All refereeing and responses will be handled by e-mail and/or fax.

- To expedite refereeing, authors should suggest three or four qualified referees for each Communication. JMR may choose from these referees or may appoint other referees depending on circumstances.

- JMR's goal is a four-week or less review turnaround time for Communications.

We hope that these new procedures will provide the materials community with a rapid outlet for high quality rapid transmission of exciting new results.

ROBERT A. LAUDISE

Editor-in-Chief

PATRICK K. GALLAGHER Communications Editor

\title{
Parental Volunteer Introduces Materials Science to First Graders
}

When my son Michael's first grade teacher asked for parental volunteers in the classroom, I offered to do a science demonstration introducing materials science. She was skeptical but humored me by agreeing. I decided that in order to grab the children's attention, and keep it, I would involve them in hands-on experiments.

In my introduction to the class of about 25 students, I explained that I was a teacher and scientist who worked in the materials engineering department in a university and that I and my colleagues did research on various types of materials. Our goals were to design and produce new materials and improve existing ones. Next, I told the students that the various materials could be divided into three main types: metals, polymers, and ceramics. In addition, some materials are made up of a combination of these (composites). I explained that the different types of materials had different properties. Metals are generally strong and tough (do not break easily), ceramics are hard and brittle, and plastics are often fairly soft and flexible. I showed some examples: a plastic bag and elastic band for polymers, a steel hammer for metals, and a coffee mug and plate for ceramics. I then asked the students to point out examples in their classroom. I was somewhat surprised at their enthusiasm, as virtually every hand in the room went up (it would be nice to have about a tenth of that enthusiasm in my university classes). I chose seven or eight students; the ones not chosen were visibly disappointed. I reassured them that I would try to involve everyone through the course of the demonstrations and experiments. The students grasped the basic concepts of the materials and listed some very good examples, including the legs on their desks (metals), windows (ceramics), and plastic toys and pencil cases (polymers).

After the basic introduction, I asked for assistants to experiment with materials. The hands went up again. The first experiment was intended to demonstrate the effect of cold temperatures on the properties of materials, specifically the toughness. I had a piece of tin rod, some plastic tubing, and an elastic band. Before starting, I had the students identify the materials. (I explained safety considerations, and volunteers had to wear safety glasses for their own protection as well as for effect. In the future I would like to add child-sized lab coats.) My first assistant demonstrated his strength to the class by bending the tin rod. I then asked him to try to break the rod with a hammer. He tried and tried, but the best he could do was to deform the rod. This, of course, clearly demonstrated the toughness of a metal at room temperature. Another volunteer did the same with the plastic tubing. The tubing was very flexible and could not be broken with a hammer. I then produced a dewar of liquid nitrogen (children just love liquid nitrogen), which I explained was a very cold liquid, about $200^{\circ} \mathrm{C}$ below zero, that looked just like water. To give them some perspective as to how cold $-200^{\circ} \mathrm{C}$ is, I told them that a very cold winter day in Edmonton was $30^{\circ} \mathrm{C}$ below zero. My assistants placed the plastic tubing and tin into the liquid nitrogen. The plastic was removed with tongs and hit with a hammer, whereupon it shattered into many pieces. The same was done for the tin, which broke into a few pieces. The materials were covered with a cloth before being hammered to prevent broken material from flying about. I emphasized to the class that many materials that are tough at room temperature may not be very tough at lower temperatures. I mentioned a garden hose (a polymer) as an example. It is very flexible when used in the summer, but becomes very brittle and may crack if left outside during the winter. I also gave other more important engineering examples. I stressed that one important part of the job of a materials engineer or scientist is to design and make materials that have the required properties for all possible conditions. As a final point, I showed that the plastic tubing regains its flexibility when warmed back to room temperature. The experiment was repeated with another volunteer using the elastic band.

The second experiment involved the use of a wire made from memory metal (Ni-Ti alloy). I explained that some metals were able to effectively remember their shapes, so that if deformed the metal could be returned to its original shape by heating. The wire I had was coiled up like a spring, which I straightened out. I gave another assistant the wire and a hair dryer. She was instructed to hold the wire by one end and direct the hair dryer at the wire. The students were amazed to 
see the wire spring back to its original shape. With another volunteer, I repeated the experiment-this time with a cup of hot water. I finished by mentioning a potential application of memory metals, i.e., car bumpers made of memory metal could be easily repaired with a hair dryer. The teacher commented that one of her fellow teachers was accident-prone and could benefit from such an innovation. I pointed out that the cost would probably prohibit this sort of application.

For the third experiment, I demonstrated that metals melt into liquids, just like ice melts into water. This seemed to peak the students' interest since they apparently never considered that an object as solid as steel could actually melt. Using a propane torch, I melted some pieces of tin rod from the first experiment in a ceramic crucible. I explained that I had to use a crucible or container with a higher melting temperature than the metal $\left(232^{\circ} \mathrm{C}\right.$ for tin). After a few minutes, the tin melted and I poured it into a glass beaker filled with water. This demonstrated that the metal could refreeze into a solid

\section{Advertisers in This Issue}

Page No.

Academic Press

63

American Institute of Physics $\quad 28$

High Voltage
Engineering Europa inside front cover

Huntington Laboratories back cover

Institute of Physics 15

Linn High Therm 19

MKS Instrument, inc. $\quad 40$

\begin{tabular}{ll}
\hline n\&k Technology & 39 \\
\hline
\end{tabular}

New Focus inside back cover

Philips Analytical X-Ray

40

Plenum Publishing Corporation

12

Virginia Semiconductor, Inc. 14, 20

Voltaix

9

Carl Zeiss, Inc.

56

For free information about the products and services offered in this issue, fill out and mail the Reader Service Card, or FAX it to (312) 922-3165.
The Education Exchange highlights the experiences of scientists and engineers with local schools, along with helpful hints and resources. If you would like to share your own involvement in science education, contact: Finley Shapiro, Department of Electrical and Computer Engineering, Drexel University, Philadelphia, PA 19104, U.S.A. Phone (215) 895-6749; fax (215) 895-1695; e-mail: shapiro@ece.drexel.edu

For the fourth experiment I created nylon (a polymer) with assistance from the teacher since I did not want the students to work with the type of chemicals involved. Before starting I explained that nylon is a polymer which is used in many types of clothing, such as their jackets. The chemicals had been premixed so that I only had to add solution A (hexamethylenediamine) to solution B (tetrachloroethylene and sebacoyl chloride). I then pulled out a strand of nylon about $20 \mathrm{ft}$ long from a $35 \mathrm{ml}$ solution. As I pulled out the strand I wound it onto a glass rod. After I thoroughly rinsed the nylon, the teacher helped me stretch it out to its full length.

Our final experiment involved a look at high-temperature superconductors (ceramic). I explained that wire used for electricity and electrical appliances was made from metals, such as copper, which are very good conductors. I also explained that polymers and ceramics are usually poor conductors of electricity and are often used as insulators to prevent electrical shocks. One exception, I said, is a new type of ceramic which is a very good conductor or a super conductor. I showed a pellet of $\mathrm{YBa}_{2} \mathrm{Cu}_{3} \mathrm{O}_{7-x}$ and pointed out that it only becomes superconducting when cooled to low temperatures with liquid nitrogen. I then, with the help of volunteers, showed the simple test for superconductivity, the Meissner Effect. While a magnet was levitating on the superconductor, I had each assistant pass items (such as an elastic band) between the magnet and superconductor to show that no wires or strings were involved. While the children did not understand what was happening, they were awestruck by the floating magnet.

To close the demonstrations and experiments, I asked the students to name the three types of materials again and to give examples. They did extremely well. Their teacher pointed out that although the experiments may have appeared to be magic tricks, they were indeed scientific experiments.

Overall, the materials science experiments were a success. The students understood reasonably well what we had done, with the exception of the superconductor experiment (this was not surprising as the physics of superconductivity is not easily explained in simple terms). They were encouraged to ask questions throughout, which they did, and I questioned them as well. The entire process lasted about an hour and a half, about twice as long as I originally figured. I did not anticipate the degree of enthusiasm on the part of the students. I would not recommend more than an hour and a half, as the children started to get restless near the end. I think they learned a little about materials and particularly liked being involved. As much as the students enjoyed themselves, I think I enjoyed myself even more.

The teacher invited me to return the following year to demonstrate the experiments with her new class. The experiments were equally successful and the children just as inquisitive and enthusiastic. When I finished, several of them asked more questions and chatted with me. Some of the children said that they wanted to be scientists, and one girl even asked for my autograph. She was followed by several other autograph hounds. Who would have thoughtmaterials science groupies?

My son is now in second grade and I demonstrated experiments with his new class. My theme was related to chemistry of gases. His classmates wanted to repeat some of the experiments from the previous year. I first quizzed them to see what they had remembered. They were able to name the three types of materials and give examples. Virtually everyone remembered the memory metal and one child even remembered the bumper example I had given before. Needless to say, I was extremely gratified.

Douglas Ivey is a professor of metallurgical engineering in the Department of Mining, Metallurgical and Petroleum Engineering at the University of Alberta, Edmonton, Alberta, Canada. The materials science demonstrations and experiments were performed in J. Auschrat's class at Greenfield Elementary School in Edmonton.

To receive additional information on how you can get involved in enhancing $\mathrm{K}-12$ science education, circle number 120 on the Reader Service Card. 